\title{
Electronic atlas of sea anemones: an OBIS pilot project
}

\begin{abstract}
For most of the Earth's biota, especially invertebrate and marine organisms, too few accurately and precisely identified museum specimens exist to take advantage of applications being developed to collect, collate, and interpret collection data electronically. Assembled from the primary literature, my species-centered electronic database to sea anemones of the world contains a definitive list of nominal species, each in its original binomen, with full bibliographic citation. For each species, the database lists any type specimens, and contains images of some of them, including images from the original description. Latitude, longitude, and depth, according to the original description, constitute the geographical component of the database; coordinates can be displayed on a map and queried. Localities from publications other than the original description are being added, and synonymous names are being linked. Enhancing the number of records per species, these steps will allow a geographical range to be defined for each species. Taxa allied to sea anemones will be added, and biotic and environmental datasets are being assembled so the database can be used to test biogeographical, systematic, and ecological hypotheses.
\end{abstract}

\section{Background}

Biogeographic knowledge of sea anemones (sensu lato: orders Actiniaria, Corallimorpharia, and Ptychodactiaria of cnidarian class Anthozoa) is rudimentary. Establishing the range of most taxa, which is desirable for purposes such as fisheries, conservation, and biogeographic analyses, requires consulting the original literature.

Monographs that summarize published and unpublished occurrence data exist for few taxa of anemones or parts of the world (e.g. Dunn, 1981, 1983, respectively). Some field guides provide no range data for sea anemones (e.g. Allen and Steene, 1994), and of those that do, some limit such data to the region for which the guide is written. The inventory of species is virtually complete in well-studied areas (e.g. the British Isles: Manuel, 1981; the coast of Washington state and southern British Columbia: Fautin et al., 1987) and for - well-studied groups (e.g. hosts of anemonefishes: Fautin and Allen, 1992). However, for most taxa and most parts of the world, guides refer only to the most conspicuous, distinctive species. Even for them, names and identifications may be inconsistent from one guide to another (e.g. Colin and Arneson, 1995, and Gosliner et al., 1996, for the tropical Pacific), which confounds assembly of range data from such sources.

A major reason for this dearth of information is the small number of active anemone taxonomists-at present and in the past. Trained expertise is necessary for accurate identification of most species, at least until their variability alive and preserved has been well documented. A corollary to the lack of expertise is that, although museum collections of sea anemones exist, many specimens in most of them are identified poorly or not at all. To my knowledge, catalogs of few collections of anemones have been made available on line by the institutions holding the specimens.

In these regards, sea anemones are typical of marine invertebrates other than the relatively small number of commercial value (most as food or curios). Thus, the rapidly expanding electronic ability to collect, collate, and interpret museum collection data to assess distributions is not useful for most marine taxa. Currently and into the foreseeable future, a system such as that described by Vieglais et al. (2000), to "mine" computerized museum catalogs for geographical information, cannot document much more than the fact of the existence of some taxa-data are few, they are of unreliable or undocumented quality, and some species of anemones are not represented by identified museum specimens, so any museum-based inventory will be incomplete.

\section{Database Structure And Function}

I, with the help of many students, have begun to assemble a database (currently using Microsoft Access(C) that contains a definitive list of all nominal species of sea anemones, along with associated data (Fautin, 1999). Given the state of knowledge described above, these data can be derived only from the primary literature. 
The species constitutes the core of the database, each name being verified by its full bibliographic citation. As of January 2000, 1347 nominal species had been validly published - that is, according to the International Code of Zoological Nomenclature (ICZN, International Commission on Zoological Nomenclature, 1999). Included in the database from the original description of each species are images (except those for which use permission was denied), and information about where the species was found. The latter data form one element of the geographic component of the database.

The exemplar of each species, as stipulated by the ICZN, is a single specimen, the holotype, or a series of specimens, the syntypes. The database includes a list of confirmed type specimens, including the museum cata$\log$ number of each, and original images of many of them. Type specimens exist for a surprisingly large proportion of sea anemones: of the 560 species having names beginning with the letters a through $\mathrm{g}$, I have confirmed type specimens for 281 , or $50 \%$. Data associ-

\section{NORTH ATLANTIC: type localities}

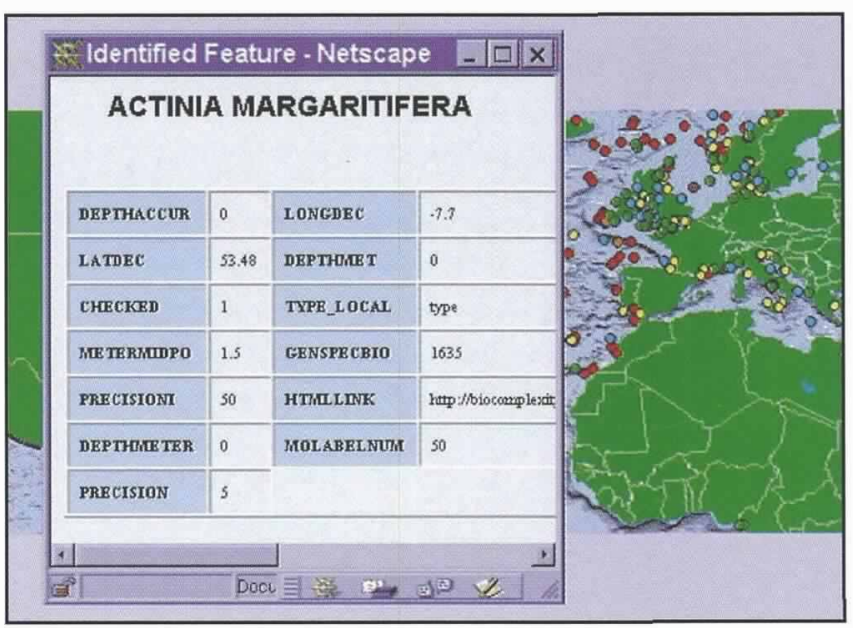

Figure 1. Type localities of sea anemones in the northeast Atlantic Ocean. Color-coding conveys precision of the information: red is a precision of 1 (most exact), yellow a precision of 3 , and aqua a precision of 5 . Clicking on one of the points identifies it as the type locality of Actinia margaritifera, and provides the associated data plus a link to the complete record.

ated with type specimens - on specimen labels or in museum catalogs - may convey locality information in addition to or more precise than that published in the species description. The place from which a type specimen was collected is the type locality.

Currently, the database contains 1615 type localities, at least one for nearly all the 1347 nominal species. Localities given in the primary literature as place names have been georeferenced. The data are assembled in ArcView (a product of Environmental Systems
Research Institute: ESRI). Using MapObjects Internet Map Server (also a product of ESRI), locality point(s) for a particular species can be displayed on a map as part of the species record, or clicking on a point on a world map showing all type localities brings up the name(s) of species for which that is the type locality (Figure 1). The species name links the point to information on bibliographic citation, type specimens, and images of the species.

Information about precision of the datapoints is integral to the geographic data. Precision of Cartesian coordinates is classified from 1 (latitude/longitude given in the original description) to 6 (locality in the original description is a continent or ocean). Points can be included in or excluded from searches according to their precision. For example, for a list of sea anemones described from the Indian Ocean, a precision of 6 would suffice. If, however, only species from the Bay of Bengal were of interest, points with precision 6 or 5 (locality in the original description is a sea, gulf, or country) could be excluded. Visually, information on precision is conveyed by color (Figure 1) or dot size, depending on the nature of the display. A locality given as "New Guinea" (precision 5) is placed at the center of the island to avoid any implication of a particular coast as the source of the specimen(s). For depth, there are two levels of precision $-1=$ inferred, and $0=$ exact from reference. An entry of 9999 in the precision field for depth or locality signifies an absence of data.

Searches of the geographical data in all three dimensions can be made using ArcView, and query results for latitude/longitude can be displayed with MapObjects. A comparison of the number of species described from high southern and northern latitudes produced the following results:

$\begin{array}{ccc}\text { From latitudes higher than } & 50^{\circ} & 60^{\circ} \\ \text { N } & 195 \text { species } & 76 \text { species } \\ \text { S } & 70 \text { species } & 38 \text { species }\end{array}$

A centralized (rather than a distributed) database such as this requires considerable labor to assemble the relevant literature and enter the information. This drawback is outweighed, in my opinion, by control over data quality and format. Quality of the data entered are maintained by proof-reading and other internal checks. Although quality of the published information is obviously beyond our control, I presume the effort necessary to assemble and write up the data constitutes a filter against the sort of novice identifications or best guesses that bedevil museum records. Errors, nonetheless, exist, some of which can become obvious through the databasing process itself. A type locality published as $38^{\circ} \mathrm{N}$ was displayed in the mountains of northern California; the specimen label confirmed the published longitude was correct but the latitude was actually $33^{\circ} \mathrm{N}$, which meant the anemone had been collected from the ocean off Los Angeles. 


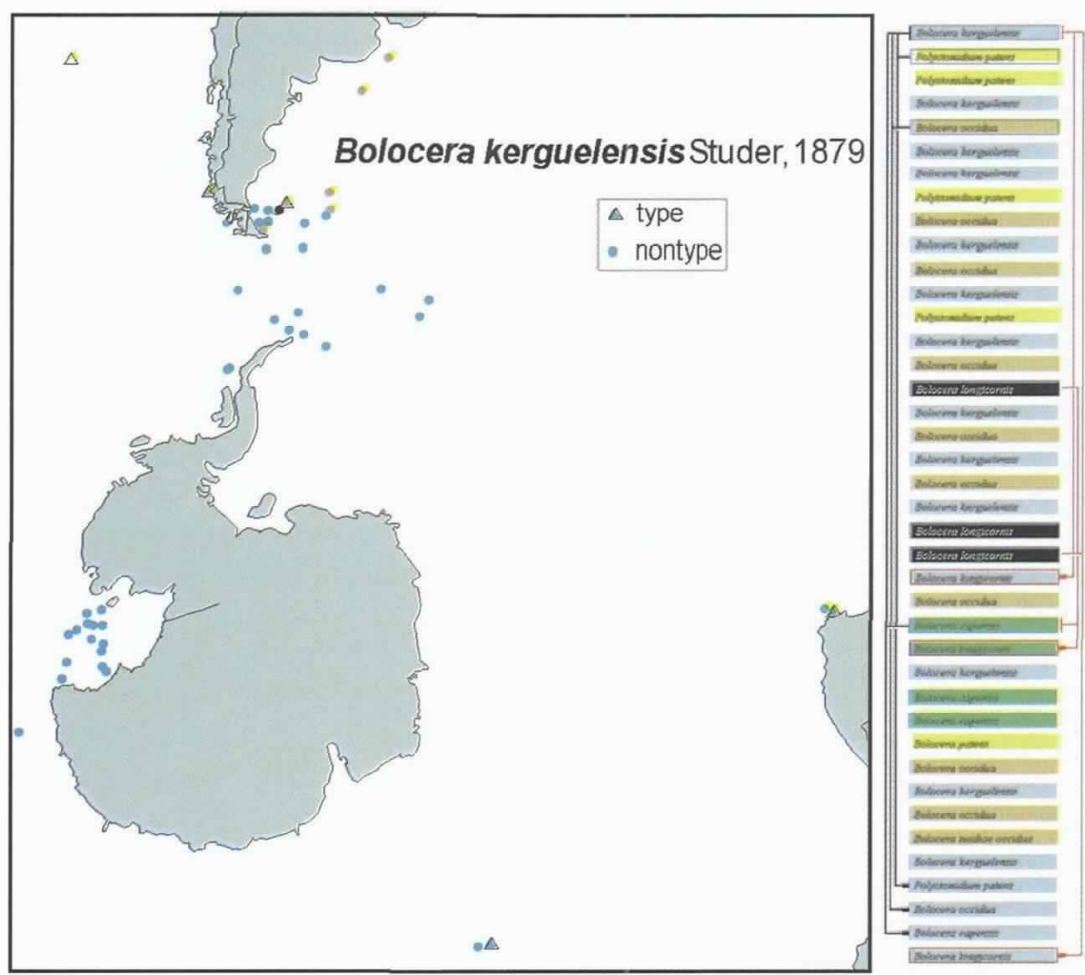

Figure 2. Published localities (both type and non-type) of Bolocera kerguelensis. Localities for B. kerguelensis and the four species that have been proposed as synonyms of it are represented by different colors that are coded as in the synonymies list at right.

(Precision of exact latitude/longitude records secured from a source other than the original publication, such as a station log or a specimen label, is coded 2.)

\section{Enhancing Biogeographic Knowledge}

Range is an emergent property; an accurate range requires many records. Therefore, information based on type localities alone is unsatisfactory for most geographical analyses. The number of records per species can be increased in two ways.

We have begun to add published records from other than the original description (see Figure 2 for an example). As part of this task, we are developing a gazetteer. By assigning coordinates and precision to a feature such as "Agulhas Bank,"inconsistencies in georeferencing are minimized or eliminated, and time is saved looking up the feature in an atlas each time it is encountered in the literature. Station lists for expeditions are also part of the gazetteer.

However, the documented range of a large proportion of anemones is restricted to the place or places from which it was first recorded. Of the 846 species considered by Carlgren (1949) to be valid, 486 (57\%) are listed in his catalog as being known only from the original description. By my reckoning, half a century later that remains true for about $45 \%$ of those species, and even for some species described since Carlgren's catalog was published, distributional data are lacking (e.g. Fautin et al., 1988). There is no satisfactory way to enhance geographic knowledge of these species: they are so poorly known it is likely that ostensible museum records other than of the type specimens of them would be suspect.

The other way to increase records per species is to link synonymous names. Of the 1347 nominal species of sea anemones, perhaps as many as 150 have been described since the publication of Carlgren's (1949) catalog, in which 846 were recognized. The difference between 846 and about 1200 is because of synonymy. A species may be described under more than one name because the species is variable, because it is widespread, or because subsequent authors were unaware that the species had been described. W. N. Eschmeyer (California Academy of Sciences; personal communication) estimated the ratio of nominal:valid species in fishes is 2:1. If Carlgren's inventory is correct, the ratio is lower for anemones. Another sort of synonymy involves transfer of a species from one genus to another. Currently the database includes original binomens only: a species is listed in combination with the name of the genus in which it was described. As the concept of a genus changes, species may be moved to and from it. Such taxonomic changes multiply the number of genus/species combinations.

Thus, plotting distributions by names on museum labels or in publications is likely to overestimate the number of species and underestimate the range of many of them. Therefore, we have developed a program to link names that have been proposed to be synonymous and to plot the distribution of specimens identified in publication by the synonymous names. In the list of synonyms and plot of localities, nominal species (whether in a single genus or not) are colorcoded (Figure 2). In addition to conveying geographical information, the visual representation of distribution allows assessment of whether the proposed synonymy is likely to be correct. If points representing different nominal species are disjunct, there may be reason to question the synonymy. Reciprocally, plotting the distribution of species that are suspected to be synonymous can provide data relevant to taxonomic issues.

The next step in development of this database is to add other taxa of hexacorallian anthozoans - scleractinian corals, tube anemones, and zoanthids. My speculation that the major hexacorallian taxa have broadly complementary distributions (Fautin, 1989) can be tested by assessing the concordance (or lack thereof) in the distributions of these animals. Simultaneously, a library of environmental databases is being assembled 
that will allow overlaying distributions of anthozoans on those of sea surface temperature, bottom type, bathymetry, etc. to understand the parameters that govern where these animals occur, and to test other biogeographical and ecological hypotheses.

Ultimately this database is planned to encompass a distributed component, with links to electronic museum catalogs to which functionalities we are currently developing for the published record can be applied. For example, a search using one binomen will result in a search by all of that name's synonyms. The site from which each museum collection was taken will be plotted as well as listed, and be coded by the name used in the collection. This will help improve the quality of museum information through a process of reciprocal illumination.

\section{Acknowledgments}

Supported by National Science Foundation grant 9521819 (PEET), and particularly by two REU (Research Experience for Undergraduates) supplements to it, including one in the Special Competition in Bioinformatics. This project would have been impossible without the help of REU students Jeremy Bartley, Jeff Henning, and M. David Fullerton, and PEET graduate student Adorian Ardelean. Robert W. Buddemeier provided valuable assistance to manuscript preparation.

\section{REFERENCES}

Allen, G.R. and R. Steene, 1994: Indo-Pacific Coral Reef Field Guide. Tropical Reef Research, Singapore, $378 \mathrm{pp}$.

Carlgren, O. 1949: A survey of the Ptychodactiaria, Corallimorpharia and Actiniaria. Kungl. Svenska Vetenskapsakademiens Handlingar, series 4, 1(1), 1-121.

Colin, P.L. and C. Arneson, 1995: Tropical Pacific Invertebrates. Coral Reef Press, Beverly Hills, California, 296 pp.

Dunn, D.F., 1981: The clownfish sea anemones: Stichodactylidae (Coelenterata: Actiniaria) and other sea anemones symbiotic with pomacentrid fishes. Trns. of the Am. Phil. Soc., 71(1), 1-115.

Dunn, D.F, 1983: Some Antarctic and Sub-Antarctic sea anemones (Coelenterata: Ptychodactiaria and Actiniaria). Antarctic Research Series, 39(1), 1-67.
Fautin, D.G., 1989: Anthozoan dominated benthic environments. In: Proceedings of the Sixth International Coral Reef Symposium, 3, 231-236.

Fautin, D.G., 1999: Sea anemones of the world: catalogue of species, bibliography of literature in which they were described, and inventory of existing type specimens. Version 2.0. http://biocomplexity.nhm.ukans.eduanemones/images/Version.html

Fautin, D.G. and G.R. Allen, 1992: Field Guide to Anemonefishes and their Host Sea Anemones. Western Australian Museum, Perth, $160 \mathrm{pp}$. [electronic version http://www.keil.ukans.edu/ ebooks/intro.html]

Fautin, D.G., A.E. Siebert and E.N. Kozloff, 1987: Class Anthozoa. In: Marine Invertebrates of the Pacific Northwest. E.N. Kozloff, ed., University of Washington Press, Seattle and London, 68-78.

Fautin, D.G., R.A. Eppard, and R.W. Mead, 1988: Acontiophorum niveum (Cnidaria, Anthozoa), a new species of acontiate sea anemone, with descriptions of actinian families Mimetridiidae and Ramireziidae. Wasmann J. of Bio., 45(1-2), 26-33.

Gosliner, T.M., D.W. Behrens, and G.C. Williams, 1996: Coral Reef Animals of the Indo-Pacific. Sea Challengers, Monterey, California., 314 pp.

International Commission on Zoological Nomenclature, 1999: International Code of Zoological Nomenclature, 4 th edition. International Trust for Zoological Nomenclature, London, $306 \mathrm{pp}$.

Manuel, R.L., 1981: British Anthozon: Keys and Notes for the Identification of the Species. Academic Press, London and other cities, $241 \mathrm{pp}$.

Studer, T., 1879 (for 1878): Zweite Abtheilung der Anthozoa polyactinia, welche während der Reise S.M.S. Corvette Gazelle um die Erde gesammelt wurden. Monatsberichte der Akademie der Wissenschaften, Berlin 25, 524-550.

Vieglais, D. E.O. Wiley, C.R. Robins and A.T. Peterson, 2000: Harnessing museum resources for the Census of Marine Life: The FISHNET Project, Oceanography, 13-3. 